\title{
Do bioresorbable polyesters have antimicrobial properties?
}

\author{
Lukas Gritsch $\mathbb{1}^{1,2} \cdot$ Christopher Lovell ${ }^{2}$ Wolfgang H. Goldmann ${ }^{3}$. \\ Aldo R. Boccaccini ${ }^{1}$
}

Received: 22 September 2017 / Accepted: 6 December 2017 / Published online: 16 January 2018

(C) The Author(s) 2018. This article is an open access publication

\begin{abstract}
Biodegradable and bioresorbable polyesters (BBPEs) are a widespread class of aliphatic polymers with a plethora of applications in the medical field. Some reports speculate that these polymers have intrinsic antibacterial activity as a consequence of their acidic degradation byproducts. The release of organic acids as a result of the hydrolytic degradation of BBPEs in vivo and the resulting $\mathrm{pH}$ drop could be an effective inhibitor of the growth of pathogens in the local environment adjacent to BBPE-based devices. However, there is no clear and conclusive evidence in the literature concerning the antibacterial activity of BBPE to support or refute this hypothesis. In this communication we address this point through an assessment of the antibacterial properties of six well-established commercially available BBPEs. Agar diffusion assays and optical density measurements at $600 \mathrm{~nm}$ were performed on all the polymer samples to characterize the growth of bacteria and any potential inhibition over an incubation period of $24 \mathrm{~h}$. The results indicated that BBPEs do not possess an intrinsic and immediate antibacterial activity, which is consistent with the clear mismatch between the time-scales for bacterial growth and the rate of degradation of the polyesters.
\end{abstract}

Aldo R. Boccaccini

aldo.boccaccini@ww.uni-erlangen.de

1 Institute of Biomaterials, University of Erlangen-Nuremberg, Cauerstraße 6, 91058 Erlangen, Germany

2 Lucideon Ltd., Queens Road, Penkhull, Stoke-on-Trent, Staffordshire ST4 7LQ, UK

3 Department of Biophysics, University of Erlangen-Nuremberg, Henkestrasse 91, 91052 Erlangen, Germany

\section{Graphical abstract}

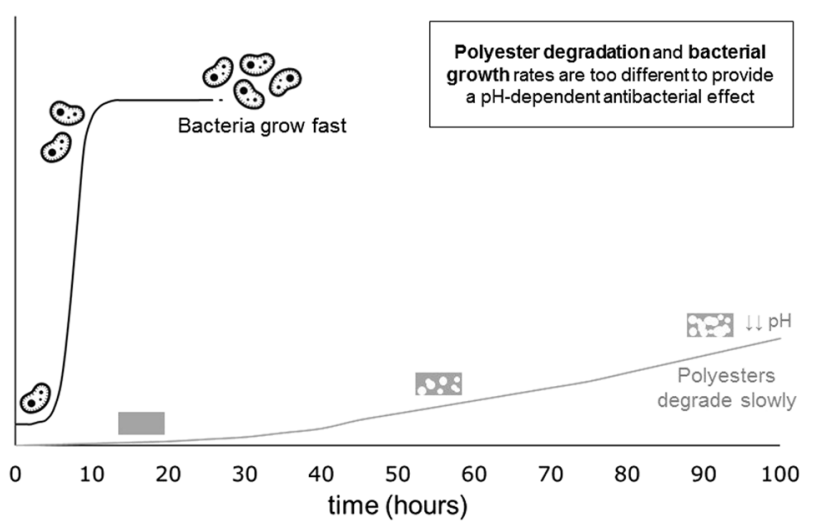

\section{Introduction}

Biodegradable and bioresorbable polyesters (BBPEs) possess numerous beneficial properties (e.g., tailorable mechanical properties, tunable degradation in contact with biological fluids, high availability at competitive costs, and drug carrying/delivering capability), which make them suitable for numerous medical applications such as surgical sutures, orthopedic clips, screws and staples, stents, tissue engineering scaffolds, coatings, and drug delivery vehicles $[1,2]$. BBPEs degrade through a hydrolytic process to form by-products, which are metabolized by the body through physiological pathways [3, 4]. Since these by-products are acidic (e.g., lactic acid), it has been proposed that the degradation might result in a drop of the local $\mathrm{pH}$ below 4 , thus inhibiting the growth of pathogens $[2,5,6]$. However, 
Table 1 Summary of the polymers used in this study

\begin{tabular}{llll}
\hline Sample & Polymer (full name) & Supplier & Molecular weight \\
\hline P1 & Poly (D,L-Lactide-co-glycolide) (PLGA) & Vornia Biomaterials, Ireland & $5-15 \mathrm{kDa}$ \\
P2 & Poly (L-Lactide) (PLLA) & Vornia Biomaterials, Ireland & $300-400 \mathrm{kDa}$ \\
P3 & Polylactic acid (PLA) & Goodfellow GmbH, Germany & N/A \\
P4 & Polyhydroxybutyrate (PHB) & Goodfellow GmbH, Germany & N/A \\
P5 & Poly ( $\varepsilon$-caprolactone) (PCL) & Sigma-Aldrich, Germany & $80 \mathrm{kDa}$ \\
P6 & Poly(D,L-Lactide) (PDLLA) & Corbion Purac, Netherlands & $80 \mathrm{kDa}$ \\
\hline
\end{tabular}

the literature lacks evidence that $\mathrm{pH}$ gradient dependent bacterial starvation actually happens in relation with the degradation of BBPEs. The statement that $\mathrm{pH}$ related antibacterial effects occur upon degradation of BBPEs is thus a hypothesis without a solid empirical validation.

In this short communication we present the results of two well-established protocols of bacterial inhibition assays performed on an array of commercially available polyesters (in film form) to assess the effect of the polymer degradation products on the growth of common strains of both Gram-positive and Gram-negative bacteria.

\section{Materials and methods}

\subsection{Preparation of the films}

Films of six different commercially available BBPEs were prepared by solvent casting. The polymers selected in this study are summarized in Table 1.

All polymers were dissolved in $20 \mathrm{~mL}$ of dichloromethane (DCM) at a fixed concentration of $5 \% \mathrm{w} / \mathrm{v}$. The solutions were then poured into glass petri dishes and left to dry at room temperature for $48 \mathrm{~h}$. After drying, disk shaped samples (films of $\varnothing=12 \mathrm{~mm}$ and $0.2 \mathrm{~mm}$ thickness) were cut from the as-cast film and then stored under vacuum to remove any residual solvent.

\subsection{Bacterial culture}

\subsubsection{Bacterial strains}

Gram-positive Staphylococcus carnosus and Gram-negative Escherichia coli were chosen as model bacterial strains for the biological testing. Prior to the experiment, suspensions of the selected strains in nutrient broth were prepared as follows: a bacterial colony was suspended in $5 \mathrm{~mL}$ of lysogeny broth (LB broth \#968.1, Carl Roth $\mathrm{GmbH}$ ) and grown overnight in an orbital shaker at $37^{\circ} \mathrm{C}$. The obtained suspension was diluted to adjust its optical density to reach the value of 0.015 at OD $600 \mathrm{~nm}$ (Biophotometer Plus, Eppendorf AG, Hamburg, Germany).

\subsubsection{Halo tests}

Antibacterial agar diffusion assays (halo tests) were carried out according to a previously developed protocol [7]. Briefly, $20 \mu \mathrm{L}$ of the prepared bacterial suspension was deposited and spread homogeneously onto a petri dish of $10 \mathrm{~cm}$ diameter, which was previously covered with a uniform layer of fresh agar (LB Agar (Lennox), Lab M Ltd.). The polyester samples were then placed onto the agar and the culture was incubated for $24 \mathrm{~h}$ at $37^{\circ} \mathrm{C}$ and high relative humidity $(\sim 80 \%)$. After the incubation time, the inhibition zone around each sample was assessed. High-resolution images of the agar plates were taken with a digital camera (Nikon D90).

\subsubsection{Optical density}

For turbidity measurements, samples of all types of polyester were immersed in $5 \mathrm{~mL}$ of the prepared bacterial suspension at an optical density of 0.015 , measured with the same Biophotometer Plus, as previously described, and incubated in an orbital shaker at $37^{\circ} \mathrm{C}$. At given time-points $(1,3,6$, and $24 \mathrm{~h})$ aliquots of the bacterial suspensions were withdrawn and the variations in optical density were analyzed.

\section{Results}

\subsection{Halo tests}

After $24 \mathrm{~h}$ of incubation the polyesters showed no inhibition area, either with Gram-positive or -negative bacteria. The results of the halo tests were generally negative and bacteria grew without any visible alteration around the samples (Fig. 1). Based on these simple results, it is safe to conclude that the tested commercial polymers have no antimicrobial effect on the selected strains. Furthermore, it is can be stated that the absence of inhibition is due to the lack of change in $\mathrm{pH}$ around the sample. 


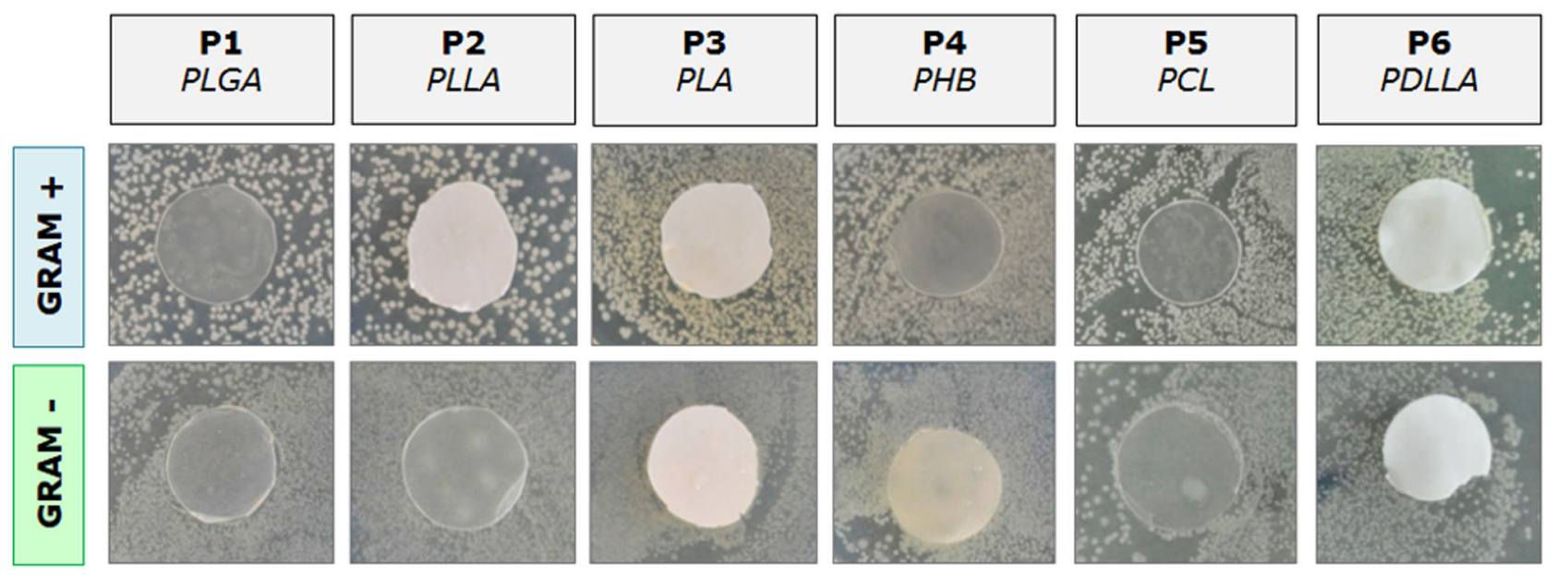

Fig. 1 Area of inhibition of tested polyesters against both Gram + (Staph. carnosus) and Gram- (E. coli) bacteria after $24 \mathrm{~h}$
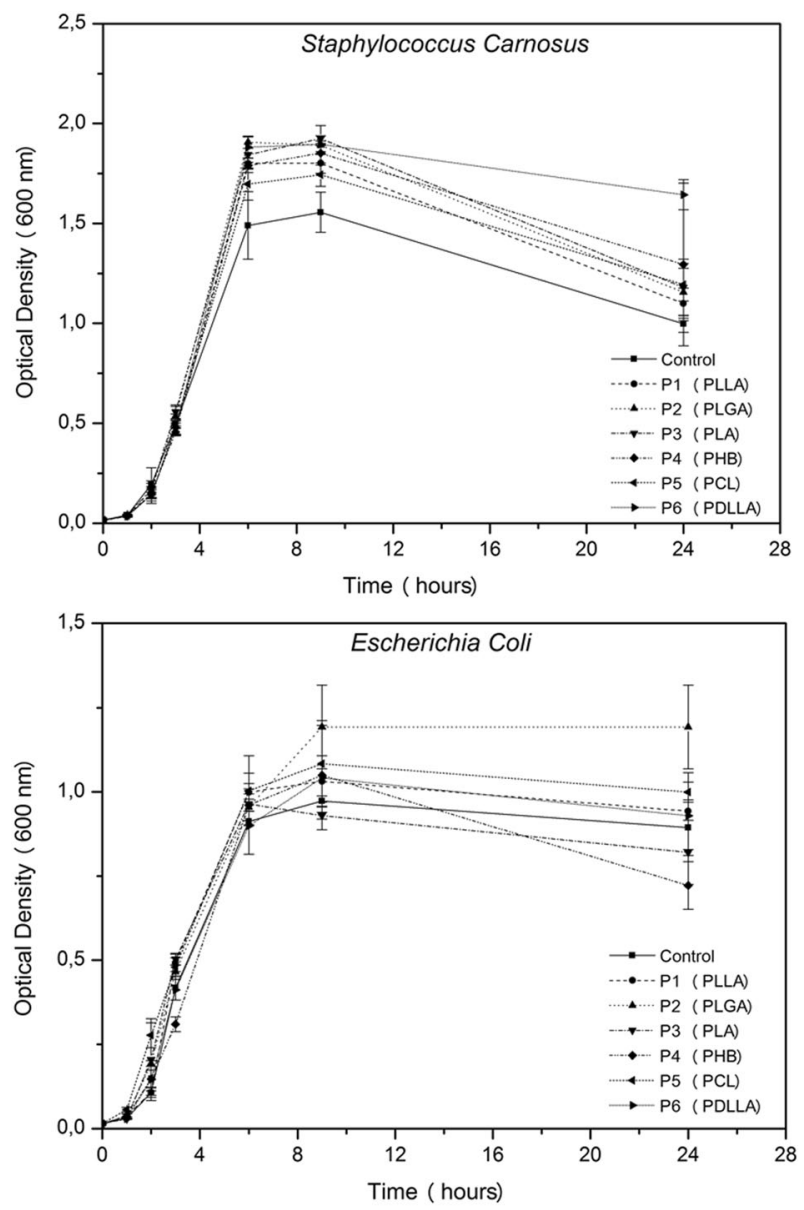

Fig. 2 Turbidity measurements on suspensions of both tested strains in LB medium. All curves follow the standard development of unconditioned bacteria growth for the different BBPEs investigated

\subsection{Optical density}

Similar results were obtained also from turbidity measurements, as shown in Fig. 2, confirming that all six polyesters have no significant effect on the growth of bacteria suspended in medium. All curves resemble a typical sequence of bacterial growth [8] and are comparable $(p<0.05)$ to the control. Measurements of the $\mathrm{pH}$ of the suspensions revealed that no $\mathrm{pH}$ drop occurred. This can be a consequence of both the buffer capability of the medium and the lack of any consistent degradation of the materials within the considered period of time.

\section{Discussion}

It is well known that most common pathogens can grow effectively only within a pH window of 4 to 9 [9-12]. Moreover, organic acids have been proven to be an effective inhibitor of bacterial growth since they interfere with the normal functions of the bacterial membrane [11-13]. The internal $\mathrm{pH}$ of bacteria must remain close to neutral even when the external $\mathrm{pH}$ changes. Bacteria maintain homeostasis by means of ion pumps, however, if the shift from neutrality is too large, $\mathrm{H}^{+}$ions start to migrate into the cytoplasm, acidifying it. This effect alters the ionization of biomolecules, inhibits the activity of enzymes and transmembrane proteins and disrupts the plasma membrane [8]. These phenomena act concurrently, gradually blocking the ability of correct cellular respiration of the microorganism. From the cell growth point of view, the pH-dependent bacterial inhibition will have an effect only at the level of maximum population, with no influence on the lag phase or the rate of growth [8].

Our results highlight that the mechanisms described above cannot take place because of the existence of a fundamental time mismatch between the degradation-driven $\mathrm{pH}$ drop and the growth of bacteria. While the former is a relatively slow process, occurring over periods of weeks to months, the latter happens within circa 1-2 days. As a 
consequence, the inhibition of bacteria caused by low $\mathrm{pH}$ described above cannot occur and the bacteria form a strong and resilient colony long before the materials evaluated herein start to degrade, negating de facto a possible $\mathrm{pH}$ dependent antimicrobial effect. A potential way to overcome this discrepancy would be to have a fast degrading polymer that is able to acidify the $\mathrm{pH}$ of the biological environment within a few hours. However, in this case, there could be an increased risk of inflammation of the surrounding tissues. Indeed, previous reports on PLA-based orthopedic implants identify the local $\mathrm{pH}$ drop as one of the main causes of chronic inflammation and, eventually, of failure $[14,15]$. These facts highlight the need to characterize in-depth the interaction between bacteria and degrading BBPEs to confirm whether the hypothesized antimicrobial activity of these polymers can be a promising strategy in fighting bacteria, which could see an expansion of the scope of medical applications of BBPEs.

\section{Conclusions}

In order to test the hypothesis, often found in literature, that biodegradable bioresorbable polyesters can have a $\mathrm{pH}$ dependent antimicrobial effect, an array of six commercially available BBPEs have been biologically characterized. Two well-established assays were performed on test strains of both Gram-positive and Gram-negative bacteria. No pHdependent antimicrobial effect of any analyzed polyester (in film form) was detected. Since there is a strong rate difference between the fast growth of bacteria and the relatively slow degradation of the polymers, no inhibition can occur. Therefore, our results disprove that BBPEs are intrinsically antimicrobial.

Acknowledgements This work has received funding from the European Union's Horizon 2020 research and innovation program under the Marie Sklodowska-Curie actions (HyMedPoly project, Grant Agreement No. 643050) and from the German Research Foundation (DFG Go598). We thank the HyMedPoly consortium for its support. We would also like to acknowledge the valuable help of Ms. Francesca Ciraldo, Ms. Astrid Mainka, and Ms. Alina Grünewald.

\section{Compliance with ethical standards}

Conflict of interest The authors declare that they have no conflict of interest.

Open Access This article is distributed under the terms of the Creative Commons Attribution 4.0 International License (http://crea tivecommons.org/licenses/by/4.0/), which permits unrestricted use, distribution, and reproduction in any medium, provided you give appropriate credit to the original author(s) and the source, provide a link to the Creative Commons license, and indicate if changes were made.

\section{References}

1. Albertsson A-C, Varma IK. Aliphatic polyesters: Synthesis, properties and applications. Adv Polym Sci. 2002;157:1-40.

2. Li S. Synthetic biodegradable medical polyesters. In: Zhang X (ed.) Science and principles of biodegradable and bioresorbable medical polymers. Cambridge, UK: Woodhead Publishing; 2017. p. 37-78.

3. Nelson DL, Cox MM. Lehninger principles of biochemistry. 4th ed. New York: W.H. Freeman and Company; 2005.

4. Vert M, Mauduit J, Li S. Biodegradation of PLA / GA polymers: increasing complexity. Biomaterials. 1994;15:1209-13.

5. Hild N, Tawakoli PN, Halter JG, Sauer B, Buchalla W, Stark WJ, et al. pH-dependent antibacterial effects on oral microorganisms through pure PLGA implants and composites with nanosized bioactive glass. Acta Biomater. 2013;9:9118-25.

6. Miyazaki H, Kinoshita M, Saito A, Fujie T, Kabata K, Hara E, et al. An ultrathin poly(1-lactic acid) nanosheet as a burn wound dressing for protection against bacterial infection. Wound Repair Regen. 2012;20:573-9.

7. Ur Rehman MA, Ferraris S, Goldmann WH, Perero S, Bastan FE, Gautier di Confiengo G, et al. RF co-sputtering of silver nanocluster-silica composite coatings on peek/bioactive glass layers: multi-structured coatings obtained by the combination of electrophoretic deposition and RF co-sputtering. ACS Appl Mater Interfaces. 2017;9:32489-97.

8. Madigan MT, Parker J, Martinko JM. Brock biology of microorganisms. 9th ed. Harlow, UK: Pearson Education Limited; 2000.

9. Klein S, Lorenzo C, Hoffmann S, Walther JM, Storbeck S, Piekarski T, et al. Adaptation of Pseudomonas aeruginosa to various conditions includes tRNA-dependent formation of alanylphosphatidylglycerol. Mol Microbiol. 2009;71:551-65.

10. Korting HC, Lukacs A, Vogt N, Urban J, Ehret W, Ruckdeschel G. Influence of the pH-value on the growth of Staphylococcus epidermidis, Staphylococcus aureus and Propionibacterium acnes in continuous culture. Zent Hyg Umweltmed Ger. 1992;193:78-90.

11. Presser KA, Ratkowsky DA, Ross T. Modelling the growth rate of Escherichia coli as a function of $\mathrm{pH}$ and lactic acid concentration. Appl Environ Microbiol. 1997;63:2355-60.

12. Valore EV, Park CH, Igreti SL, Ganz T. Antimicrobial components of vaginal fluid. Am J Obstet Gynecol. 2002;187:561-8.

13. Cherrington CA, Hinton M, Mead GC, Chopra I. Organic acids: Chemistry, antibacterial activity and practical applications. Adv Microb Physiol. 1991;32:87-108.

14. Amini AR, Wallace JS, Nukavarapu SP. Short-term and long-term effects of orthopedic biodegradable implants. J Long Term Eff Med Implant. 2011;21:93-122.

15. Ambrose CG, Clanton TO. Bioabsorbable implants: Review of clinical experience in orthopedic surgery. Ann Biomed Eng. 2004;32:171-7. 